\title{
Ultraviolet light-induced water-droplet formation from wet ambient air
}

\author{
By Keitaro Yoshihara, ${ }^{* 1, \dagger}$ Yoshiki TAKATORI, ${ }^{* 2}$ \\ Koji MIYAZAKI $^{* 3}$ and Yoshizumi KAJII ${ }^{* 3}$ \\ (Communicated by Kenichi HondA, M.J.A.)
}

\begin{abstract}
We report the formation of water droplets by irradiating wet ambient air with deep UV light. The light sources were either a continuous low-pressure mercury lamp or pulsed ArF laser, which both emit light shorter than $200 \mathrm{~nm}$. Water droplets were produced in reaction vessels under different temperature, relative humidity, and moisture-supply conditions. The particles grew as large as about $0.2 \mathrm{~mm}$. The suggested mechanism is discussed with the photodissociations of oxygen and successively formed ozone, and further dark reactions giving hydrogen peroxide as a seeding nucleus. Observed concentrations of intermediates were well explained by simulating the proposed chemical reactions. A possible application to artificial rain is briefly described.
\end{abstract}

Keywords: water droplet formation, wet air, photochemical seeding, ultraviolet light, nucleation of water, hydrogen peroxide

\section{Introduction}

In 1946 Langmuir produced clouds by cooling the air with dry ice and further proposed nucleation of water by adding foreign materials as a seed. ${ }^{1-3)}$ Techniques such as spraying chemicals like silver iodide and sodium chloride or dropping coolant materials like dry ice to cold wet air have been studied. ${ }^{1-4)}$ Essentially this same technique has been used for more than 60 years for the creation of artificial rain by many workers, since water is indispensable for human life.

As early as 1869, on the other hand, Tyndall described smoke formation by irradiating "nitrite of butyl" with an "electric light" in the presence of hydrogen chloride gas. ${ }^{5)}$ Light-induced aerosol formation from gaseous molecules is a unique method of phase transformation, but it has not been a popular subject. Recently laser-assisted aerosol and

*1 Toyota Physical and Chemical Research Institute, Aichi, Japan.

*2 Toyota Central R\&D Laboratory, Aichi, Japan.

*3 Department of Applied Chemistry, Tokyo Metropolitan University, Tokyo, Japan.

$\dagger$ Correspondence should be addressed: K. Yoshihara, Toyota Physical and Chemical Research Institute, 41-1, Yokomichi, Nagakute, Aichi 480-1192, Japan

(e-mail: Riken-Yoshihara@mosk.tytlabs.co.jp). liquid droplet formations from various kinds of gases (alkali metal, a mixture of $\mathrm{NO}_{2}$ and $\mathrm{SO}_{2}$, and benzene) have been reported. ${ }^{6)-9)}$ Very recently we discovered that the pulsed UV-laser irradiation of ambient air induces the formation of water droplets or small ice particles in the laboratory. ${ }^{10)}$ Here we report that a weak ordinary continuous light source forms droplet/mist from wet ambient air under several different experimental conditions and propose a possible mechanism of "photochemical seeding".

\section{Experimental method}

Reaction vessels and mode of operation. The reaction vessel was a hollow quartz tube with a diameter of $150 \mathrm{~mm}$ and height of $150 \mathrm{~mm}$, and. we used it in three different modes. 1) For the diffusion-type experiment, namely topwarm/bottom cold conditions, several layers of thick, wet felt cloth were placed on the top and a block of dry ice or ice on the bottom. The produced particles stayed still in this mode of operation. 2) For the convection-type experiment, namely topcold/bottom-warm conditions, a water pan was placed on the bottom, and a flat metal pan filled with cooling materials was placed on the top of the hollow tube. The particles moved vigorously 
A

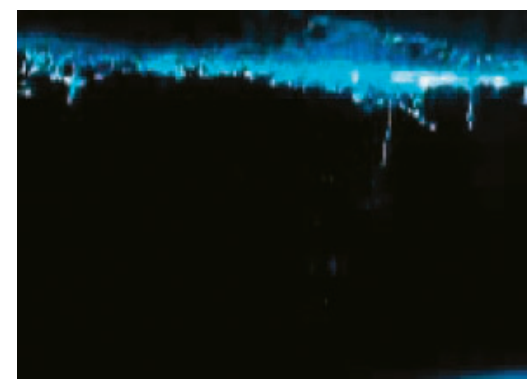

B

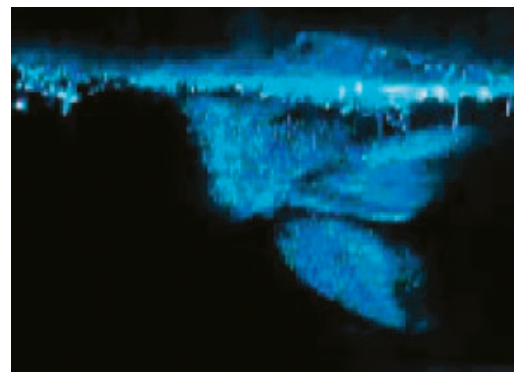

C

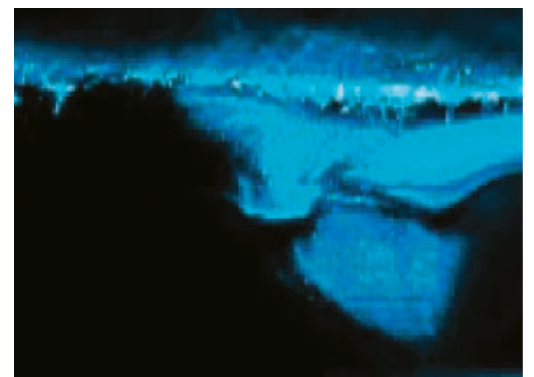

Fig. 1. Light scattering induced by continuous deep UV-light irradiation from a low pressure mercury lamp (7 W) in a diffusion-type reaction vessel. Fig. 1A shows light scattering before light irradiation, only the wet felt cloth can be seen. Figs. $1 \mathrm{~B}$ and $1 \mathrm{C}$ show light scattering after 1 and $2 \mathrm{~min}$ light irradiation, respectively. Fine droplets are observable. Temperature at $1 \mathrm{~cm}$ below the felt cloth was $22^{\circ} \mathrm{C}$. The photo shows an area of about $5 \mathrm{~cm} \times 3.5 \mathrm{~cm}$.

due to convection flow. 3) For smaller temperature gradient operations, both top and bottom pans were filled with ice.

Light sources. We used either a continuous (in time) UV light from a small low-pressure mercury $(\mathrm{Hg})$ lamp (7 W, photons at 185, 254, $313 \mathrm{~nm}$, etc.) or a pulsed ArF laser (200 mJ/pulse at $193 \mathrm{~nm}$ ) without forcussing operated at $5-20 \mathrm{~Hz}$.

Observation of reaction intermediates. The chemical intermediates of ozone and the $\mathrm{HO}_{2}$ radical could be observed simultaneously by changing the lamp intensity (see Discussion). The absolute concentration of ozone was determined by absorption intensity in the UV region using a Dylec $\mathrm{O}_{3}$ analyzer (Model 1150). The $\mathrm{HO}_{2}$ radical at pptv (parts per trillion in volume) level was measured by a new method, peroxy radical amplification combined with laser-induced fluorescence measurement (PERCAL/LIF) which recently was developed for environmental research in Kajii laboratory at Tokyo Metropolitan University. ${ }^{11)}$ The sensitivity of the system was so high that in some cases we had to reduce the lamp intensity to about $0.05 \mathrm{~W}$. The observed concentrations were about. $10^{2}$ ppbv level for $\mathrm{O}_{3}$ and about $10^{2}$ pptv level for the $\mathrm{HO}_{2}$ radical.

Materials. Ambient air was used in most of the experiments. As a reference we used pure air from a cylinder (Sogo Gas Co., G2 grade), which gave the same results as ambient air. Pure water (Wako/Dojin, deionized, filtered water) was used. These experiments indicate that impurities in the ambient air do not play any significant role in water-droplet formation. When air was replaced by nitrogen gas the phenomenon was not induced. The photochemical product $\mathrm{H}_{2} \mathrm{O}_{2}$ was detected in the water pan by coloring 4-aminoantipyrin with coenzyme (Kyoritu, WAK- $\mathrm{H}_{2} \mathrm{O}_{2}$ ) and by ion chromatography (Nihon Dionex, ICS-2000) with amounts of typically $0.1 \mathrm{mg} / \mathrm{l}$ after $1 \mathrm{~min}$ irradiation by the Hg lamp (about $0.5 \mathrm{~W}$ ). The temperature and relative humidity were measured by semiconductor detectors (SATO SK-LHII $\alpha-2$ ).

Particle observation. Fine particles are formed by UV-light irradiation and light scattered by the droplets can be readily observed with a flashlight. For a better record, we used an Ar ion laser beam (blue, $488 \mathrm{~nm}$ ) or a laser pointer (green) which was stretched to $2 \mathrm{D}$ by a cylindrical lens. Particle formation and the dynamics were recorded by a digital camera (Panasonic DMC-FZ5) in movie mode at 30 frames/s.

\section{Results}

Droplet/mist/ice-particle formation. 1) In the diffusion-type operation, Fig. 1A shows the center of the vessel before UV-light irradiation; the felt cloth can be seen on the top. Figs. 1B and $1 \mathrm{C}$ show a strong light scattering after 1 and $2 \mathrm{~min}$ of light irradiation, respectively. The area of particle formation was expanded further for prolonged irradiations (figure not shown). The particles stayed still in this diffusion-type vessel. The temperature at $1 \mathrm{~cm}$ below the felt cloth was $22^{\circ} \mathrm{C}$ and at $1 \mathrm{~cm}$ above the dry ice on the bottom it was $12{ }^{\circ} \mathrm{C}$. In this experiment relatively large droplets up to about $0.2 \mathrm{~mm}$ in diameter were produced.

2) In a convection-type vessel with UV light from a pulsed ArF laser, we observed either mist or ice- 
A

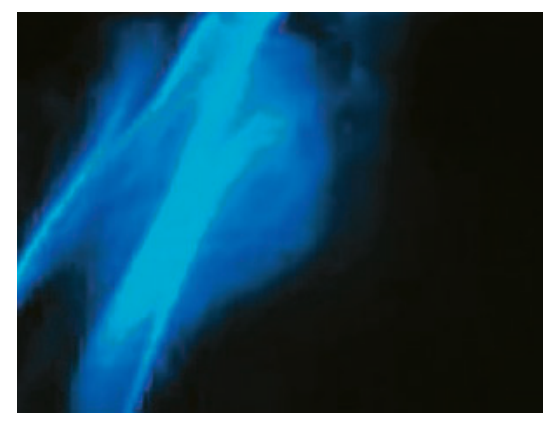

B

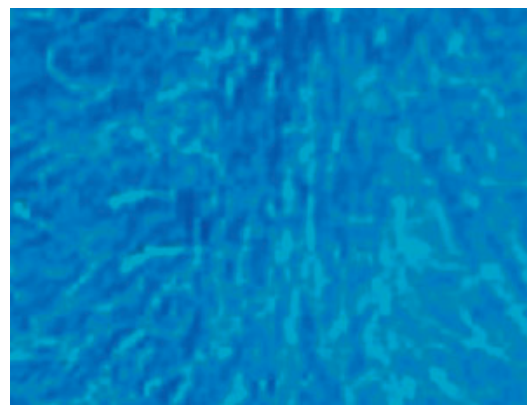

Fig. 2. Details of typical light scattering patterns observed upon irradiation by an ArF laser at different temperatures in a convection-type reaction vessel. Fig. 2A shows a scattering pattern of fine particles when the top of the vessel was cooled by ice/ water. The measured temperature near the surface of the top pan facing the vessel was $0-3^{\circ} \mathrm{C}$. Fig. $2 \mathrm{~B}$ shows the pattern of moving traces of coarse particles when the top of the vessel was kept much colder, cooled by dry ice/ethanol. The bottom surface of the top pan was heavily covered by frost and the temperature near the surface was $-10^{\circ} \mathrm{C}$. Water in the bottom pan was controlled between $20-25^{\circ} \mathrm{C}$. The photo shows an area of about $3.0 \mathrm{~cm} \times 2.3 \mathrm{~cm}$.

A

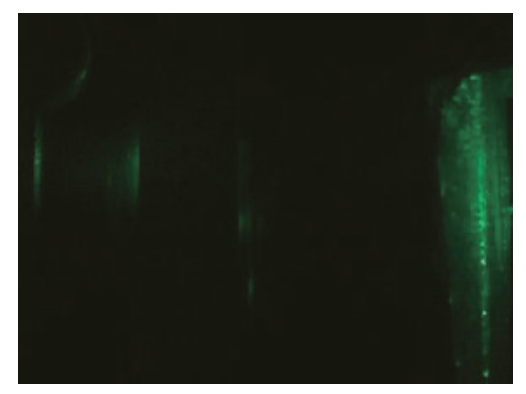

B

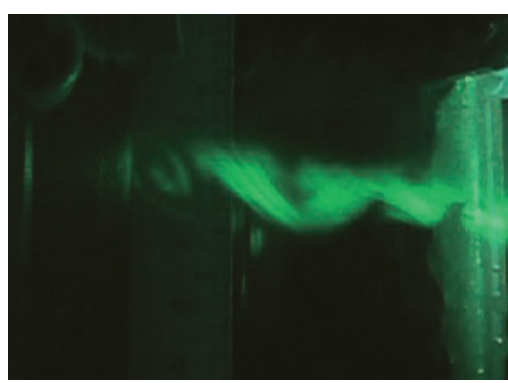

C

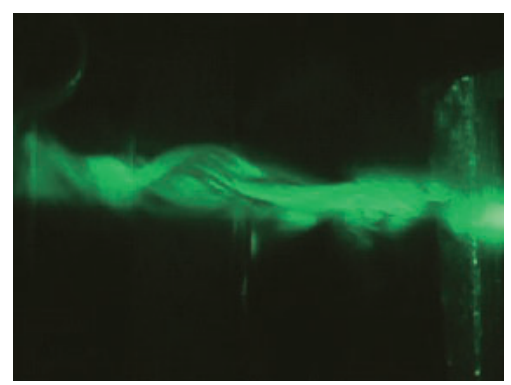

Fig. 3. Light scattering induced by continuous UV-light irradiation from a low pressure mercury lamp of only $0.3 \mathrm{~W}$, in a reaction vessel without much temperature gradient. Fig. $3 \mathrm{~A}$ shows the scattering before light irradiation. Temperature was $13^{\circ} \mathrm{C}$ at the center of the reaction vessel and relative humidity was about $87 \%$. Green color is due to light scattering observed through the quartz window using a laser pointer. Figs. 3B and $3 \mathrm{C}$ show views taken at $5 \mathrm{~s}$ and $8 \mathrm{~s}$ after the UV light was turned on.

particles depending on temperatures. The measured temperature inside the vessel near the bottom surface of the top pan was about $0{ }^{\circ} \mathrm{C}$ for ice/water and about $-10^{\circ} \mathrm{C}$ for dry ice/ethanol. In the former case, light scattering due to fine mist started to appear soon after laser excitation (typically, $5 \mathrm{~Hz}$ for $10 \mathrm{~s}$ ) at various undefined places at the bottom of the top pan. The mist moved down, mainly by convection flow, and disappeared quickly. An example of light scattering by such a mist is shown in Fig. 2A. Mist appeared many times intermittently and continued long (more than $10 \mathrm{~min}$ ) after the laser irradiation had been terminated. In the latter case (dry ice/ethanol), a much stronger scattering of numerous coarse particles appeared throughout the vessel as shown in Fig. 2B. The phenomenon continued for a long time even after the excitation had been terminated. The particles moved vigorously and often formed whirlpools and were considered to be ice particles. The size of the larger particles was about $0.3 \mathrm{~mm}$.

3) For smaller temperature gradient operations, mist was formed in the reaction vessel with ice in both the bottom and top pan. The temperature at the middle part of the vessel was about $12-15^{\circ} \mathrm{C}$. In this particular experiment air with about $100 \%$ relative humidity was supplied to the vessel at a rate of $2 \mathrm{~L} / \mathrm{min}$. Irradiation with a $\mathrm{Hg}$ lamp as low as $0.3 \mathrm{~W}$ induced mist formation within a few seconds, as shown in Fig. 3. 


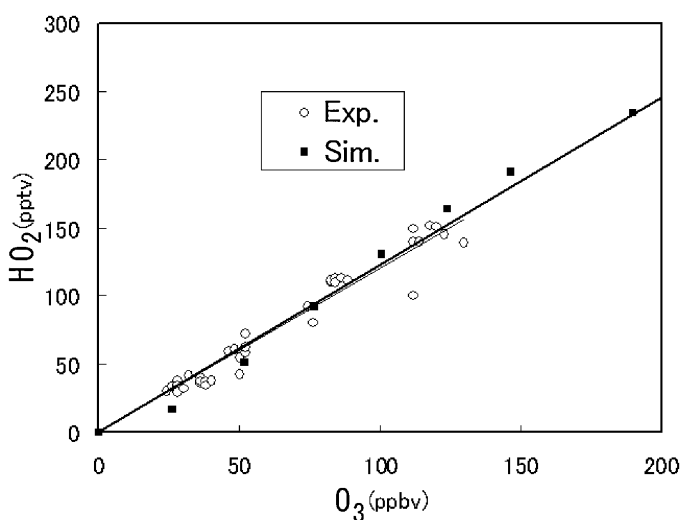

Fig. 4. The correlation of concentrations of $\mathrm{O}_{3}$ and $\mathrm{HO}_{2}$ radical at $23{ }^{\circ} \mathrm{C}$ and $>95 \%$ relative humidity by sweeping the light intensity at about $0.05 \mathrm{~W}$ from a mercury lamp. The empty circles show experimental results and filled squares show the simulation calculations (see text).

Measurement of reaction intermediates. As mentioned above the simultaneous observation of reaction intermediates of ozone and $\mathrm{HO}_{2}$ radical was made upon sweeping $\mathrm{Hg}$ lamp intensity at about $0.05 \mathrm{~W}$ as shown in Fig. 4 . At this concentration range the $\mathrm{HO}_{2}$ radical grew linearly with $\mathrm{O}_{3}$ concentration. The results of our simulation (see later section) are also shown in the same figure. We avoided mist formation during intermediate detection and the experiment was conducted at room temperature. The total flow rate in the reaction tube was set to $4 \mathrm{~L} / \mathrm{min}$. In this experiment the air flow was created by sending air through wet fiber, which produced wet air of high humidity at this flow rate. ${ }^{12)}$

\section{Discussion}

Reaction mechanism. Based on the results of our experiment and simulation, we propose a mechanism which involves the photochemical dissociation of oxygen and ozone and the following dark reactions. Oxygen dissociates to atomic oxygen $\left({ }^{3} \mathrm{P}\right)$ with either $185 \mathrm{~nm}(\mathrm{Hg}$ lamp) or $193 \mathrm{~nm}$ (ArF laser) light excitation (R1). The atomic oxygen quickly reacts with oxygen molecules to form ozone (R2). ${ }^{13)-16)}$ The second photochemical reaction by ozone takes place to form atomic oxygen $\left({ }^{1} \mathrm{D}\right)$ (R3), since ozone has a very strong absorption in the UV region at around $250 \mathrm{~nm}$ and shorter wavelengths. It efficiently reacts with $\mathrm{H}_{2} \mathrm{O}$ to produce an $\mathrm{OH}$ radical (R5). The $\mathrm{OH}$ reacts with ozone to produce an $\mathrm{HO}_{2}$ radical (R6) and two
Table 1. Reactions included in simulation

\begin{tabular}{ll}
\hline $\mathrm{O}_{2}+\mathrm{h} \nu \rightarrow \mathrm{O}+\mathrm{O}$ & $\mathrm{O}+\mathrm{O}_{3} \rightarrow \mathrm{O}_{2}+\mathrm{O}_{2}$ \\
$\mathrm{O}+\mathrm{O}_{2} \rightarrow \mathrm{O}_{3}$ & $\mathrm{O}\left({ }^{1} \mathrm{D}\right)+\mathrm{O}_{2} \rightarrow \mathrm{O}+\mathrm{O}_{2}$ \\
$\mathrm{O}_{3}+\mathrm{h} \nu \rightarrow \mathrm{O}$ & $\mathrm{O}\left({ }^{1} \mathrm{D}\right)+\mathrm{O}_{3} \rightarrow \mathrm{O}_{2}+\mathrm{O}_{2}$ \\
$\mathrm{O}_{3}+\mathrm{h} \nu \rightarrow \mathrm{O}\left({ }^{1} \mathrm{D}\right)$ & $\mathrm{O}\left({ }^{1} \mathrm{D}\right)+\mathrm{O}_{3} \rightarrow \mathrm{O}_{2}+\mathrm{O}+\mathrm{O}$ \\
$\mathrm{O}\left({ }^{1} \mathrm{D}\right) \rightarrow \mathrm{O}$ & $\mathrm{O}+\mathrm{OH} \rightarrow \mathrm{O}_{2}+\mathrm{H}$ \\
$\mathrm{O}\left({ }^{1} \mathrm{D}\right)+\mathrm{H}_{2} \mathrm{O} \rightarrow \mathrm{OH}+\mathrm{OH}$ & $\mathrm{O}+\mathrm{HO}_{2} \rightarrow \mathrm{OH}+\mathrm{O}_{2}$ \\
$\mathrm{O}_{3}+\mathrm{OH} \rightarrow \mathrm{HO}_{2}+\mathrm{O} 2$ & $\mathrm{OH}+\mathrm{OH} \rightarrow \mathrm{H}_{2} \mathrm{O}+\mathrm{O}$ \\
$\mathrm{O}_{3}+\mathrm{HO}_{2} \rightarrow \mathrm{OH}$ & $\mathrm{OH}+\mathrm{OH}+\mathrm{M} \rightarrow \mathrm{H}_{2} \mathrm{O}_{2}+\mathrm{M}$ \\
$\mathrm{HO}_{2}+\mathrm{HO}_{2} \rightarrow \mathrm{H}_{2} \mathrm{O}_{2}+\mathrm{O}_{2}$ & $\mathrm{OH}+\mathrm{HO} \rightarrow \mathrm{H}_{2} \mathrm{O}+\mathrm{O}_{2}$ \\
$\mathrm{H}_{2} \mathrm{O}_{2}+\mathrm{h} \nu \rightarrow \mathrm{OH}+\mathrm{OH}$ & $\mathrm{OH}+\mathrm{H}_{2} \mathrm{O}_{2} \rightarrow \mathrm{H}_{2} \mathrm{O}+\mathrm{HO}_{2}$ \\
$\mathrm{HO}_{2}+\mathrm{O}_{3} \rightarrow \mathrm{OH}+\mathrm{O}_{2}+\mathrm{O}_{2}$ & $\mathrm{H}+\mathrm{O}_{3} \rightarrow \mathrm{OH}+\mathrm{O}_{2}$ \\
$\mathrm{HO}_{2}+\mathrm{h} \nu \rightarrow \mathrm{OH}+\mathrm{O}\left({ }^{1} \mathrm{D}\right)$ & \\
\hline
\end{tabular}

$\mathrm{HO}_{2}$ radicals form hydrogen peroxide $\left(\mathrm{H}_{2} \mathrm{O}_{2}\right)$ and $\mathrm{O}_{2}$ (R7). ${ }^{13)-15)}$ The followings show the proposed main reactions.

$$
\begin{array}{ll}
\mathrm{O}_{2}+\mathrm{h} \nu_{1} \rightarrow 2 \mathrm{O}\left({ }^{3} \mathrm{P}\right) & \mathrm{R} 1 \\
\mathrm{O}\left({ }^{3} \mathrm{P}\right)+\mathrm{O}_{2}+\mathrm{M} \rightarrow \mathrm{O}_{3}+\mathrm{M} & \mathrm{R} 2 \\
\mathrm{O}_{3}+\mathrm{h} \nu_{2} \rightarrow \mathrm{O}_{2}+\mathrm{O}\left({ }^{1} \mathrm{D}\right) & \mathrm{R} 3 \\
\mathrm{O}+\mathrm{O}_{3} \rightarrow 2 \mathrm{O}_{2} & \mathrm{R} 4 \\
\mathrm{O}\left({ }^{1} \mathrm{D}\right)+\mathrm{H}_{2} \mathrm{O} \rightarrow 2 \mathrm{OH} & \mathrm{R} 5 \\
\mathrm{OH}+\mathrm{O}_{3} \rightarrow \mathrm{HO}_{2}+\mathrm{O}_{2} & \mathrm{R} 6 \\
\mathrm{HO}_{2}+\mathrm{HO}_{2} \rightarrow \mathrm{H}_{2} \mathrm{O}_{2}+\mathrm{O}_{2} & \mathrm{R} 7
\end{array}
$$

Hydrogen peroxide is a stable hygroscopic molecule and has a high capture rate of water molecules. There also is the possibility of a complex formation of an intermediate peroxy radical $\left(\mathrm{HO}_{2}\right)$ and water which recently was confirmed spectroscopically. ${ }^{17), 18)}$ Reactions R1-R4 are known as the Chapman mechanism for ozone formation in the stratosphere. ${ }^{13)-15)}$

Simulation of the reactions. We calculated the 26 simultaneous differential rate equations of all elementary reactions (reactions in Table 1 and R8-R10) which include many more reactions in the Chapman mechanism, and got concentrations of all intermediates and products in the gas phase. ${ }^{19)}$ In particular we selected the essential reactions of the atmospheric reactions ${ }^{19)}$ and added the necessary reactions for the air/water system. The photodissociation reactions of all possible intermediates (Table 2) were also included. The kinetic parameters used for simulation are listed in references (19) and (20). The CHEMKIN II package produced by the Sandia National Laboratories was adopted for solving the differential equations. ${ }^{21}$ ) We further took into consideration of the complex formation 
Table 2. Photochemical reactions included in simulation

\begin{tabular}{|c|c|c|c|c|}
\hline \multirow{2}{*}{ Reactions } & \multicolumn{3}{|c|}{ Absorption cross section $/ \mathrm{cm}^{2}$} & \multirow{2}{*}{ Reaction quantum yield } \\
\hline & $185 \mathrm{~nm}$ & $193 \mathrm{~nm}$ & $254 \mathrm{~nm}$ & \\
\hline $\mathrm{O}_{2}+\mathrm{h} \nu \Rightarrow \mathrm{O}\left({ }^{3} \mathrm{P}\right)+\mathrm{O}\left({ }^{3} \mathrm{P}\right)$ & $1.2 \times 10^{-21}$ & $4.0 \times 10^{-22}$ & 0.0 & 1.0 \\
\hline $\mathrm{O}_{3}+\mathrm{h} \nu \Rightarrow \mathrm{O}\left({ }^{3} \mathrm{P}\right)$ & $1.0 \times 10^{-18}$ & $2.0 \times 10^{-19}$ & $1.0 \times 10^{-17}$ & 0.1 \\
\hline $\mathrm{O}_{3}+\mathrm{h} \nu \Rightarrow \mathrm{O}\left({ }^{1} \mathrm{D}\right)$ & $1.0 \times 10^{-18}$ & $2.0 \times 10^{-19}$ & $1.0 \times 10^{-17}$ & 0.9 \\
\hline $\mathrm{HO}_{2}+\mathrm{h} \nu \Rightarrow \mathrm{OH}+\mathrm{O}$ & $3.0 \times 10^{-18}$ & $4.0 \times 10^{-18}$ & $3.0 \times 10^{-19}$ & 1.0 \\
\hline $\mathrm{H}_{2} \mathrm{O}_{2}+\mathrm{h} \nu \Rightarrow \mathrm{OH}+\mathrm{OH}$ & $7.0 \times 10^{-19}$ & $6.0 \times 10^{-19}$ & $7.0 \times 10^{-20}$ & 1.0 \\
\hline
\end{tabular}

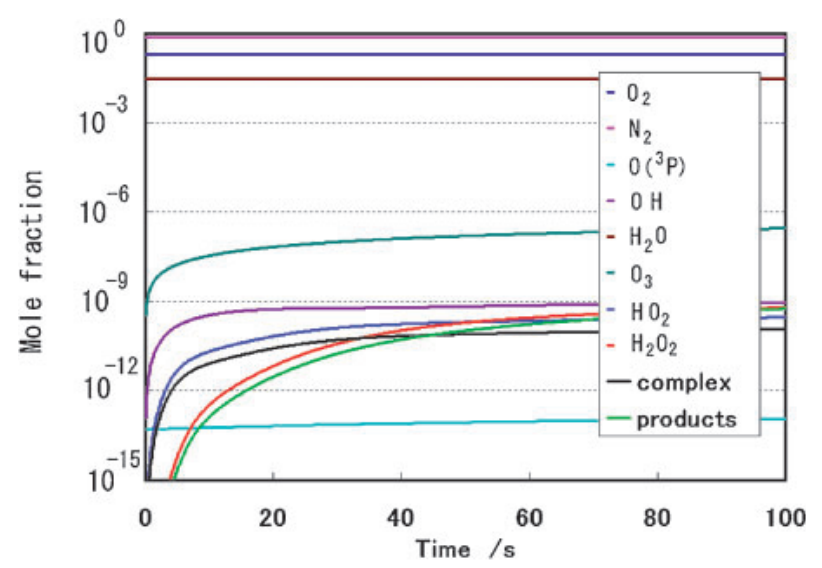

Fig. 5. Simulation of all reactions in Tables 1-2 and R8-R10 at room temperature. The ordinate in $\log$ scale indicates mole fractions of species.

of $\mathrm{HO}_{2}$ radical and water, which is in equilibrium as given by $\mathrm{R} 8^{22), 23)}$ and associated reactions, $\mathrm{R} 9$ and R10.

$$
\begin{array}{ll}
\mathrm{HO}_{2}+\mathrm{H}_{2} \mathrm{O} \rightleftarrows \mathrm{HO}_{2}-\mathrm{H}_{2} \mathrm{O} & \mathrm{R} 8 \\
\mathrm{HO}_{2}+\mathrm{HO}_{2}-\mathrm{H}_{2} \mathrm{O} \rightarrow \text { products } & \mathrm{R} 9 \\
\mathrm{HO}_{2}-\mathrm{H}_{2} \mathrm{O}+\mathrm{HO}_{2}-\mathrm{H}_{2} \mathrm{O} \rightarrow \text { products } & \mathrm{R} 10
\end{array}
$$

In this simulation the photon number was $4.0 \times 10^{12}$ at $185 \mathrm{~nm}, 9.1 \times 10^{14}$ at $253 \mathrm{~nm}$, and $6.7 \times 10^{13}$ at $313 \mathrm{~nm}$ [photon $\mathrm{cm}^{-2} \mathrm{~s}^{-1}$. The standard initial conditions for the simulations were 1 atm of air and $100 \%$ saturation of water at $300 \mathrm{~K}$, namely $31.7 \mathrm{~mol} / \mathrm{m}^{3}$ for nitrogen, $8.5 \mathrm{~mol} / \mathrm{m}^{3}$ for oxygen, and $1.43 \mathrm{~mol} / \mathrm{m}^{3}$ for water. The correlation of $\mathrm{O}_{3}$ and $\mathrm{HO}_{2}$ concentrations is shown in Fig. 4.

In Fig. 5, simulated concentrations (mole fractions) of all intermediates and the final products are shown as a function of time. The ratio of concentrations of $\mathrm{HO}_{2}$ radicals and $\mathrm{O}_{3}$ is approximately 1 to 1000 and absolute mole fractions are on the order of 100 pptv and 100 ppbv, which is in good accord- ance with the experimental results (Fig. 4). In the same figure (Fig. 4), we plotted the experimental and simulated values of concentrations of $\mathrm{HO}_{2}$ and $\mathrm{O}_{3}$. The agreement is very good and this indicates the original assumption of the reaction scheme is an appropriate one.

The vapor pressure of $\mathrm{H}_{2} \mathrm{O}_{2}$ was calculated to be about $10^{-4} \mathrm{~Pa}$ under the above conditions, while the saturated vapor pressure of $\mathrm{H}_{2} \mathrm{O}_{2}$ is about $10^{3} \mathrm{~Pa}$ at $300 \mathrm{~K}$. Thus the number density of $\mathrm{H}_{2} \mathrm{O}_{2}$ is too small to form a large amount of droplets and thus $\mathrm{H}_{2} \mathrm{O}_{2}$ cannot be the entire contents of the droplets. The capability of $\mathrm{H}_{2} \mathrm{O}_{2}$ as a seed material was briefly tested by spraying aqueous $\mathrm{H}_{2} \mathrm{O}_{2}$ solution $(25 \%)$ into a cold box. Observations by light scattering showed that the $\mathrm{H}_{2} \mathrm{O}_{2}$ created many droplets which persisted for a long time (10-20 min). As a reference experiment, spraying of pure water created particles instantly, but they disappeared immediately. We suggest that $\mathrm{H}_{2} \mathrm{O}_{2}$ works as a precursor of initial nucleation in this "photochemical seeding" system and the subsequent growth of particles proceeds through water condensation onto the particle surface followed by the formation of larger droplets.

Water is indispensable for human life, and vast areas of the planet suffer from lack of water. If our findings could be used to help scientists and engineers create a new alternative method for artificial rain, the resulting techniques could be of inestimable value. On a smaller scale, it may be possible that systems based in part on this study could be developed for more limited applications, such as the production of water in greenhouses or biospheres. The possible applications of this work are wide-ranging.

\section{Conclusions}

We discovered that deep ultraviolet-light irra- 
diation of wet ambient air induces the formation of water droplets/mist particles in different types of reaction vessels at different temperatures. Experiments simply consisted of irradiating wet ambient air with deep UV light and observing droplet/mist/ ice-particle formation by light scattering with a visible laser. The temperature was $-10-+22^{\circ} \mathrm{C}$ and relative humidity was $80-100 \%$ depending upon the conditions set in the reaction vessels. This new phenomenon takes place at a wide range of temperatures and requires neither a super-cooled condition nor supersaturation of water. Even very low-intensity UV light (for example, $0.5 \mathrm{~W}$ ) is enough to induce water droplets when wet air is supplied from outside the reaction vessel. The proposed mechanism of the initial gas phase reaction, including two consequent photo-dissociations of oxygen and successively formed ozone and the subsequent reactions were successfully proven by measuring the reaction intermediates of ozone and $\mathrm{HO}_{2}$ radicals and testing the proposed reactions by simulating 26 elementary reactions. An implication of this experiment to artificial rain was briefly described.

\section{Acknowledgements}

The authors thank Professors A. Ikushima and K. Saito of Toyota Institute of Technology for lending the laser and Mr. T. Fujikawa and Dr. H. Ito of Toyota Central R \& D Laboratories with their experimental supports. We appreciate valuable discussions with Professors H. Inokuchi, M.J.A., of Japan Aerospace Exploration Agency, N. Nakashima of Osaka City University, A. Morita of Tohoku University, M. Kawasaki of Kyoto University, Mr. S. Kubo, Mr. H. Takekawa, Mr. M. Nakano of Toyota Central R \& D Laboratories, and Ms. J. A. Steeh.

\section{References}

1) Langmuir, I. (1948) Proc. Am. Phil. Soc. 92, 167185.

2) Langmuir, I. (1950) Science 112, 35-41.
3) Langmuir, I. (1951) Trans. NY Acad. Sci. 14, 4044.

4) Kraus, E. B. and Squires, P. (1947) Nature 159, 489-491.

5) Tyndall, J. (1869) Phil. Mag. 37, 384-394.

6) Tam, A., Moe, G. and Happer, W. (1975) Phys. Rev. Lett. 35, 1630-1632.

7) Iwamoto, K., Presser, N. and Ross, J. (1978) J. Chem. Phys. 68, 663-665.

8) Ernst, K. and Hoffman, J. J. (1979) Chem. Phys. Lett. 68, 40-43.

9) Nakashima, N. and Yoshihara, K. (1982) Bull. Chem. Soc. Jpn. 55, 2783-2787.

10) Yoshihara, K. (2005) Chem. Lett. 34, 1370-1371.

11) Sadanaga, Y., Matsumoto, J., Sakurai, K., Isozaki, R., Kato, S., Nomaguchi, T., Bandow, H. and Kajii, Y. (2004) Rev. Sci. Instrum. 75, 864-872.

12) Ito, H., Sugiura, T., Nagai, H., Murase, A., Kodama, S., Inoue, Y., Yamamoto, A. and Hayakawa, K. (2007) Chromatography 28, 2528.

13) Okabe, H. (1979) Photochemistry of Small Molecules. John Wiley \& Sons, New York.

14) Jacob, D. J. (1999) Introduction to Atmospheric Chemistry. Princeton University Press, Princeton.

15) Finlayson-Pitts, B. J. and Pitts, J. N. (2000) Chemistry of the Upper and Lower Atmosphere. Academic Press, New York.

16) Matsunami, Y. and Kawasaki, M. (2003) Chem. Rev. 103, 4767-4781.

17) Suma, K., Sumiyoshi, Y. and Endo, Y. (2006) Science 311, 1278-1281.

18) Brauer, C. S., Sedo, G., Grumstrup, E. M., Leopold, K. R., Marshall, M. O. and Leung, H. O. (2005) Chem. Phys. Lett. 401, 420-425.

19) NASA, Jet Propulsion Laboratory, Chemical Kinetics and Photochemical Data for Use in Atmospheric Studies. Evaluation Number 14, 2003, http://jpldataeval.jpl.nasa.gov/.

20) Gery, M. W., Whitten, G. Z., Kllus, J. P. and Dodge, N. C. (1989) J. Geophys. Res. 94, 1292512956.

21) Kee, R. J., Rupley, F. M. and Miller, J. A. (1989) CHEMKIN-II SAND89-8009B.

22) Hamilton, Jr., E. J. and Lii, R.-R. (1977) Internatl. J. Chem. Kin. 9, 875-885.

23) Kanno, N., Tonokura, K., Tezaki, A. and Koshi, M. (2005) J. Phys. Chem. A 109, 3153-3158.

(Received Aug. 22, 2007; accepted Oct. 22, 2007) 